\title{
In search of a technical fee for endoscopy in Ontario
}

\author{
David Bach $\mathrm{MD}^{1,2}$, Paul C Adams MD², Editor-in-Chief
}

$\mathrm{R}$ adiologist Dr David Bach is the current President of the Ontario Medical Association (OMA). He is in an academic practice at University Hospital, London, Ontario, and specializes in gastrointestinal radiology and abdominal imaging. Dr Bach is an emeritus professor at the University of Western Ontario, London, Ontario.

Dr Bach's experience at the OMA includes representing the medical profession on a trilateral committee (with membership from the OMA, the Ministry of Health and LongTerm Care and the Ontario Hospital Association) that completed a comprehensive review of issues surrounding the funding and provision of the technical components of diagnostic services.

The Canadian Journal of Gastroenterology approached Dr Bach to provide insight to the fee-setting process in Ontario, particularly technical fees (T-fees) for endoscopy.

PA: Could you provide an overview of the process involved in creating a new fee in the province of Ontario, and how that fee is adopted into the provincial fee schedule?

DB: The established process for the introduction of a new fee code, or the revision of an existing fee code (including the fee amount), involves the OMA Central Tariff Committee

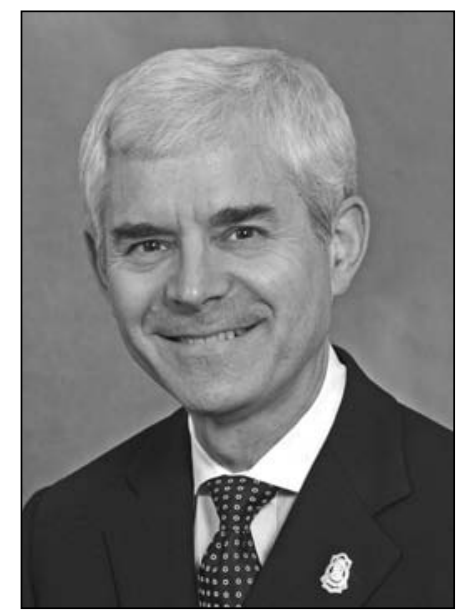

Radiologist Dr David Bach is the current President of the Ontario Medical Association. He is in an academic practice at University Hospital, London, Ontario, and specializes in gastrointestinal radiology and abdominal imaging. Dr Bach is an emeritus professor at the University of Western Ontario, London, Ontario
(CTC) and its annual 'Marathon' process.

Each year in January, the CTC invites the OMA's clinical sections to submit fee code proposals for consideration (note that the section executive must make the request). The CTC reviews all requests and prepares a recommendation for each proposal. These recommendations are then presented in the form of a report to the OMA governing council in November of the same year.

If the council accepts the recommendation, then the new fee code or revised fee code is incorporated into the OMA schedule of fees, which is different than the Ontario Health Insurance Plan (OHIP) schedule of benefits. Subsequently, the OMA recommends to the Ministry of Health and Long-Term Care that the fee be added to the OHIP schedule of benefits.

This process often occurs as part of negotiations between the OMA and the government.

PA: What is the current status of the T-fee for endoscopy in Ontario?

DB: In November 2005, the OMA council approved the CTC recommendation to create a T-fee for flexible gastroscopy or colonoscopy performed outside the hospital. The recommendation has been added to a list of outstanding CTC recommendations awaiting adoption into the OHIP schedule of benefits. The recommended fee of $\$ 146.66$ covers the anticipated costs of purchasing, cleaning and maintaining endoscopes and other required ancillary equipment; the required supplies; the salaries and benefits for the required personnel; and rent.

PA: What are the steps involved in having this T-fee approved by OHIP?

DB: The T-fee has already been approved by the OMA council and been included in the OMA schedule of fees. The next step is negotiating with the Ministry of Health and Long-Term Care for its implementation into the OHIP schedule of benefits, which may prove difficult, if not impossible. The Ministry's current position is that it will not implement the fee into the OHIP schedule of benefits, ostensibly because endoscopy is listed as a surgical procedure and as such T-fees do not apply.

PA: Why is that the case?

DB: Well, in the first place, there is a nuance here that should not be missed. The introduction of T-fees for a surgical procedure would set a precedent that we would have to consider very carefully, because the consequence of its broader application could be the diversion of funds from physician payments to hospital operating budgets. This is not in our interest, nor that of the Ministry. Additionally, it could expose the Ministry to the potential for 'double-dipping' where hospitals receive both operating funds and T-fees to support the same services. Second, we have an agreement from the Ministry to segregate the funding of technical components of diagnostic services from professional fees, and so new T-fees will require negotiation of new funding, something that is not in place at the moment. It may simply be that the Ministry thinks that the proposed fee (or associated total cost) is too high. Likely each factor comes into play in varying degrees of importance.

PA: Have there been fees approved by the OMA which have never been approved by OHIP?

DB: Approximately 95\% of all CTC recommendations are adopted into the OHIP schedule of benefits. Those that are not adopted are typically a result of the recommendation having become redundant (due to other fee revisions); a conflict with recommendations brought forth by other technical bodies (for example, the Ontario Health Technology

\footnotetext{
${ }^{1}$ Ontario Medical Association, Toronto; ${ }^{2}$ Department of Diagnostic Radiology and Nuclear Medicine, University of Western Ontario;

${ }^{3}$ Department of Medicine, London Health Sciences Centre, London, Ontario

Correspondence: Dr David Bach, Ontario Medical Association, 525 University Avenue, Suite 300, Toronto, Ontario M5G 2 K7.

Telephone 1-800-268-7215, fax 416-599-9309, e-mail david_bach@oma.org
} 
Advisory Committee) or other technical aspects that may have disqualified the fee from being adopted (for example, if the fee were deemed contrary to the Ministry's policy).

PA: If the T-fee for endoscopy is approved, will money have to be taken back from other gastroenterology fees to accommodate the new code in the OHIP schedule?

DB: No. This fee will require the Ministry to provide new funding.

PA: Radiologists have been involved with negotiations over T-fees for many years. Can we learn from this experience?

DB: It is important to clarify that radiologists do not negotiate T-fees. The OMA negotiates with the Ministry of Health and Long-Term Care on behalf of its members. T-fees are an important issue for our Association and the profession. The 2004 Physician Services Framework Agreement assigned the task of completing a thorough review of all aspects of funding diagnostic services in Ontario to a trilateral Diagnostic Services Committee. This committee meets regularly and reports to the profession.

PA: Is it likely that the T-fee approval would be dependent on whether an ambulatory endoscopy centre meets certain quality standards?

DB: The College of Physicians and Surgeons of Ontario (CPSO) is responsible for ensuring that quality standards for the performance of a service are met. The clinical practice parameters and facility standards developed by the CPSO are available on the college Web site <http://www.cpso.on.ca/ Publications/publications.htm>.

The T-fee for endoscopy is calculated on the premise that the procedures would be performed in a manner that ensures patient safety and adequate quality control, and conformance with relevant CPSO guidelines.

PA: Can any Ontario physician or gastroenterologist charge a T-fee for endoscopy?

DB: The OHIP schedule of benefits does not restrict physicians from claiming procedural fees. Any physician who by virtue of his or her training or practice experience is competent to perform a procedure is permitted to claim the appropriate fee.

PA: Concern has been raised that if this T-fee is approved, endoscopists will abandon hospitals in favour of more lucrative ambulatory endoscopy centres?

DB: This is a reasonable concern, but one must consider the costs associated with running an endoscopy centre that complies with the CPSO guidelines. The T-fee was calculated on a revenue-neutral basis to only cover the additional costs incurred for providing endoscopy outside the hospital. This may not be as lucrative as it appears. 


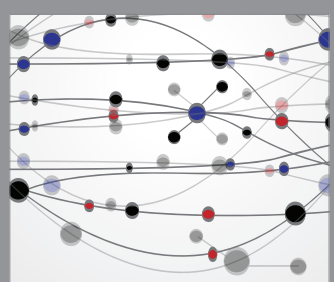

The Scientific World Journal
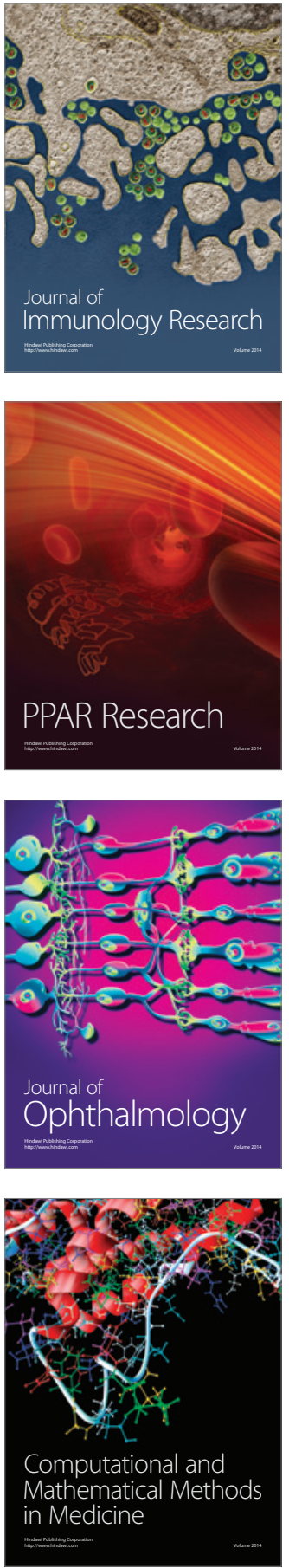

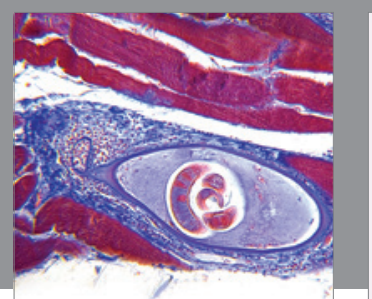

Gastroenterology Research and Practice

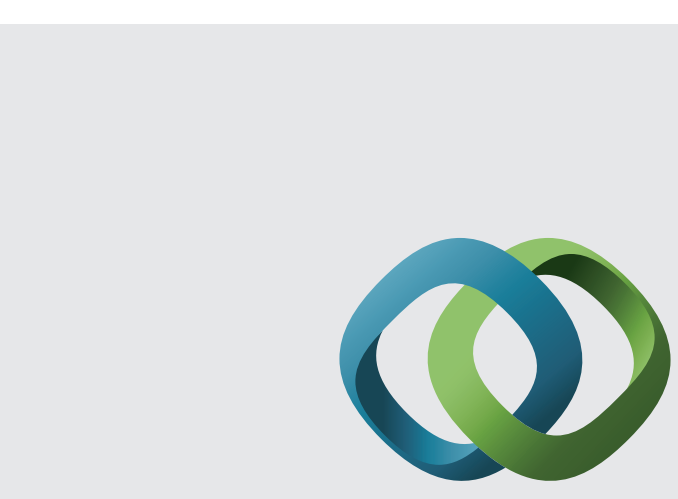

\section{Hindawi}

Submit your manuscripts at

http://www.hindawi.com
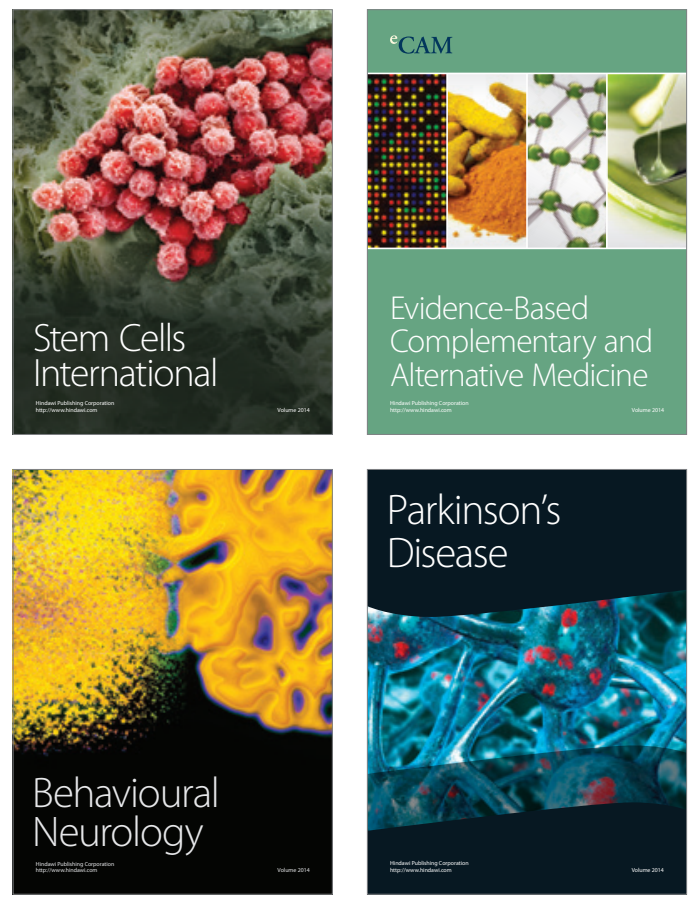
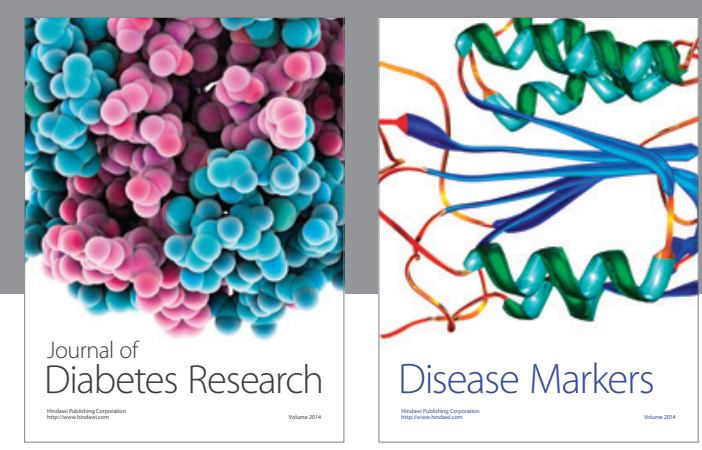

Disease Markers
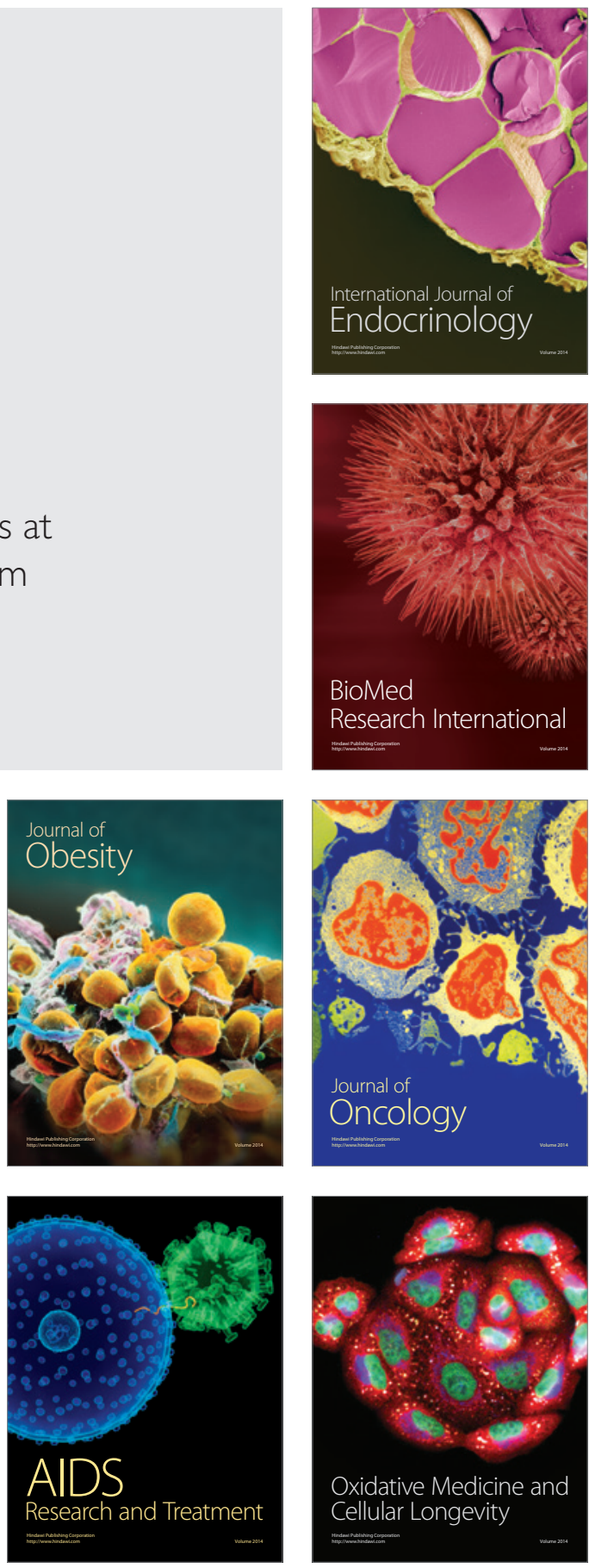